\title{
Derecho Procesal"
}

\section{CONSIDERACIONES SORRE MET ODO $Y$ CONTENIDO DE LA ENSENANZA PRACTI CA DEI. DERECHO}

\author{
por ANDRES AYLWIN AZOCAR \\ Jefe de Trabajos del Seminario de Derecho Procesal y Praclica Forense \\ de la Universidad de Chile.
}

La generalidad de las Escuelas de Derecho tienden a introducir o perfeccionar en sus programas de estudios cursos que con el nombre de "Práctica Forense". "Enseñanza Práctica", u otro semejante, se inspiran en el mismo anhelo de dar a los alumnos no sólo una buena formación teórica (que es su tarea básica) sino también de prepararlos para el ejercicio profesional.

En este trabajo nos proponcmos señalar brevemente algunas de las ideas básicas que, a nuestro juicio, deben inspirar estos cursos, ideas de las cuales surgirán como conclusiones lógicas las normas programáticas que deben guiar su desarrollo práctico.

Creemos que no es posible desarrollar debidamente el tema sin enfocarlo teleológicamente, tanto en relación con los fines de la enseñanza universitaria, como especialmente en relación con el tipo de profesional abogado que deben entregar a la comunidad las Escuelas de Derecho.

Sabemos que se ha estimado normalmente que la Universidad persigue como fines concretos el desarrollo y la trasmisión de la cultura, la investigación científica y la preparación de los futuros investigadores $u$ hombres de ciencia y la formación de profesionales o, más concretamente, la preparación para las llamadas profesiones liberales.

Pues bien, planteadas así Ias cosas resuita que la asignatura de "práctica foyense" tiende principalmente a cooperar con el último de los fines señalados: la formación de un profesional eficiente. Pero debemos dejar en claro que esa es sólo su finalidad principal, pues, a nuestro juicio, una cátedra de "Práctica Forense" bien concebida no sería ajena, directa $o$ indirectamente, al cumplimiento de los otros fines de la enseñanza superior.

Ubicada ya la asignatura en estudio en el campo de la formación profesional debemos dejar claramente establecida una prioridad de la enseñanza teórica, y por ello nadie podría discutir que las Escuelas de Derecho deben producir abogados o jueces cultos, con una buena formación teórica y con un conocimiento más o menos completo de la legislación positiva de su respectivo país. Pero si ello es muy cierto, tampoco puede merecer discusión en nuestros días que la Universidad debe entregar a la comunidad un profesional abogado también eficiente desde un punto de vista práctico.

La verdad de esta última afirmación se desprende de la sola circunstancia de que al abogado se le puede entregar la defensa de intereses importantes o cuantiosos al dia siguiente de recibir su título, entrega que el cliente hará seguramente más por confianza en la Uni-

(4) La continuación del trabajo del Profesor Hugo Percira Anabalón. Director del Seminarjo de Derecho Procesal y Práctica Forense de la U. de Ch. aparecerá en el próximo número de la Revista. 
versidad que otorgó el título que en la persona del abogado. $Y$ aunque cs cierto que el abogado empieza normalmente atendiendo el "asunto pequeño", no es menos efectivo que ese asunto pequeño puede tener para el cliente modesto tanta o mayor importancia que la que puede tener el asunto grande para el cliente de buenos recursos. Y la "falta de experiencia", que tranquiliza la conciencia del profesional joven frente al error, no puede servir de igual justificación para el instituto universitario que otorgó el título.

Precisamente por la razćn anotada el abogado recién recibido debe ubicarse en el Tribunal, conocer sus libros y saber usarlos; debe saber tratar al juez, a la contraparte y al colega; debe saber la forma práctica como se dictan las resoluciones, cómo se producen las pruebas, cómo se hacen las notificaciones, cóms se constituye el poder, cómo se ubica $\mathrm{cl}$ expediente, cómo trabaja el receptor $\mathrm{o}$ el actuario. Debe igualmente saber hacer los escritos, los recursos, las providencias, las sentencias. Debe saber usar los ficheros y ubicar los antecedentes doctrinarios o de jurisprudencia. Debe, especialmente, saber escribir y hablar en términos forenses. Para conseguir todo esto, en las clases de "práctica forense" se familiariza al alumno "con el manejo y examen de los expedientes judiciales. se ejercita en el lenguaje, estilo y ritual del foro, y se le proporcionan los medios para que conozca y aplique las reglamentaciones, usos y costumbres del Tribunal en todo lo que tenga vinculación con la actuación en juicio" (1).

La enseñanza de todas estas materias podrá, si se quiere, ser modesta. Pero no por ello de indudable utilitad. Así como también es modesto e indispensable el aprendizaje del uso del bisturí por un médico cirujano.

Planteadas asi las cosas, empezamos a ubicarnos en el tema de nuestro trabajo: el objeto y contenido de una clase de "práctica forense". Pero para ubicar las cosas más exactamente (aunque ya lo

(1) Enrique Fornatti. Estudios de Derecho Proce sal, pàg, 12. rart. sobre "Práctica Forense y Asistoncia Turidica de Pobres"). dicho sería suficiente justificación para el ramo) debemos ahondar mucho más para cvitar el riesgo de caer en simplificaciones que resten al aprendizaje práctico su verdadera importancia pedagógica.

Existe un problema que es casi inheJente a la naturaleza humana. esto es. la dificultad para aplicar el conocimiento abstracto a la realidad. Todos sabemos, y los abogados no somos ajenos al problema, cuánto cuesta aplicar el "principio al hecho "concreto". la "norma"' al "caso", el Derecho al hombre. Es cl eterno problema de la transtormación de la jdea en acción. Todos hemos visto al alumno brillante, con una buena formación teórica, que después se muevo con cierta torpeza en el ejercicin de su profesión, como si existieran dos mundos diferentes dentro de él y faltara el cngranaje que permitiera unir la idea con el acto, la Ciencia con la Técnica.

La facilidad para aplicar el conocimiento teórico a un hecho humano es indudablemente una aptitud, una habilidad. Y como todas las aptitudes, puede perfectamente ser desarrollada y enriquecida. Pues bien, el más elemental conocimiento de Pedagogía nos enseña que el desarrollo de este tipo de habilidad debe efectuarse simultáneamente con la formación teórica del alumno. (2). Y es precisamente en el desarrollo de esta aptitud humana (función primordial de cualquier establecimiento educacional) donde debemos encontrar uno de los rasgos más importantes y más definitorios de ia asignatura que estudiamos.

El problema de la "transferencia" del conocimiento de un plano a otro diferente constituya preocupación fundamental de la Ciencia Pedagógica, e incide, en el fondo, en la necesidad de que la educación contribuya a la formación de un individuo útil, capaz de cooperar

(2) Sostiene William A, Kelly que uno de los principios basicos del estudio eficaz es que el alumno haga "utilización práctica de los hechos $e$ informaciones que ha adquirido". Y agrega que "este fin debe hacerse realidad cuanto antes $y$ en la mayor medida posible" "Psicología de la Educación", pág. 332). 
al desarrollo y bienestar de la comunidad en que vive y capaz de reaccionar con eficacia frente a la situación nueva o imprevista. $Y$ precisamente por ello, cuando en una clase de Práctica Forense el profesor plantea a los alumnos ciertos hechos para que éstos los analicen $\mathrm{y}$ posteriormente los reduzcan a fórmulas juridicas (a través de un escrito hecho por ellos), el procedimiento no asume verdadera importancia por la circunstancia de que el alumno aprenda a hacer un tipo determinado de escritos idemanaa, casación, expresión de agravios) sino especialmente en cuanto contribuye al desarrollo, en el alumno, de su capacidad de creación.

Refiriéndose precisamente a este problema pedagógico expresa William $\mathrm{A}$. Kelly que "es principio fundamental de la educación que el "desarrollo sistemático del conocimiento y la destreza, la formación metódica de hábitos de pensamiento y de acción, no pueden poseer significado si no se dirigen a la realización de las más altas posibilidades humanas". Y agrega que por ello la eficacia de un sistema educacional depende fundamentalmente del hecho de que la enseñanza pueda ser "transferida", es decir, "del grado en que las potencias, capacidades y facultades del individuo funcionen frente a situaciones de la vida, de tal manera que la eficacia ganada al resolver un problema sirva también para afrontar con éxito otro u otros diferentes" (3).

$\mathrm{X}$ es precisamente por esta necesidad de que exista en los alumnos un desarrollo armónico de sus conocimientos jurídicos y de su destreza forense - base imprescindible para que exista una buena transferencia del conocimiento-que en las Facultades de Derecho, conjuntamente con la clase académica en la cual el profesor parte del principio para posteriormente estudiar la ley, debe existir también la otra clase en que el profesor plantea el hecho, para que los alumnos, aplicando la ley y sus conocimientos teóricos, viertan sus razones y su pensa-

(3) William A. Kelly. Psicología de la Educacion. 1960, pág. 332. miento en una actuación procesal concreta.

En este último tipo de clases, frente al caso planteado por el profesor (extraído de la realidad o de un expediente archivado) deberá el alumno hacer un examen de los hechos, desestimar los datos innecesarios y valorizar debidamente los con relevancia jurídica, elegir la acción y los preceptos legales en que ella debe apoyarse, hacer concretamente una demanda; deberá igualmente el alumno elegir las excepciones, fundamentarlas y darles vida en el escrito l'espectivo; deberá también estudiar el recurso con que se debe impugnar la sentencia, redactarlo y hacer verbalmente las alegaciones que correspondan, etc.. etc.

Todo este tipo de actividades pedagógicas, destinadas especialmente a des. arrollar las aptitudes del alumno, no creemos en ningún caso que sean patrimonio exclusivo de una clase de "práctica forense", pero nos parece innegable que es en ella donde con mayor facilidad pueden ser empleadas. En esta forma la asignatura de "práctica forense" es complemento indispensable de las clases de tipo académico y se encuentra destinada básicamente a dotar a los alumnos de las aptitudes necesarias para que puedan "transferir" el conocimiento por ellos adquirido del plano de la teoría al plano de la acción.

Planteada así una asignatura de "práctica forense", constituye dentro de los estudios jurídicos, la manifestación más típica del sistema de "enseñanza activa", sistema que tiene como finalicad conservar y acrecentar las energias útiles y constructivas del individuo, para hacer de él una personalidad autómata y responsable, y que sostiene que todo lo que se enseña desde fuera, sin contacto con las energías interiores, tiende a desequilibrar el ser y le es, por tanto, perjudicial y que, en cambio, todo lo que favorece las energías constructivas del alumno es la base para su formación Este método de enseñanza invade en el Universo entero no sólo la educación primaria y secundaria sino también la educación superior.

Sabemos que no decimus novedad de 
ninguna especie si expresamos que el alumno de Derecho no puede ser un mero receptor pasivo de los conocimientos que le proporciona el profesor, ni puede ser un mero repetidor de preceptos legales o de textos de estudio, ni menos puede vivir en función de memorizar lo necesario o indispensable para aprobar un examen. No. Lo importante es que el alumno, a través de su esfuerzo personal, desarrolle integramente su personalidad de hombre y de abogado, de individuo culto y de profesional eficaz. Y es precisamente por este sentido especial de la actividad creadora del alumno que en la asignatura de "práctica forense" el educando debs observar, deducir, pensar, analizar, seleccionar, investigar, discutir, escuchar al compañero, decidir y escribir. En esta forma el alumno debe aprender el Derecho casi en la misma forma en que un niño aprende a caminar: por el empleo de su propia imaginación y actividad y apenas guiado por "aIguien" que debe evitar la caída peligrosa, pero de cuya ayuda se debe tratar de prescindir.

Con esta forma de enseñanza "el alumno deja de ser un elemento pasivo, como en la exposición de la cátedra, interviniendo directamente en el planteo, desarrollo y solución de casos, ya en forma verbal o escrita, ya haciendo aplicación del texto legal con el código en Ia mano, ya deduciendo del principio jurídico abstracto la norma aplicable al caso concreto". (Eduardo B. Carlos. "Clínica Juridica y Enseñanza Práctica" pág. 71)

Así concebida la asignatura de "práctica forense" es tipicamente la clase hecha "por" el alumno y no "para" el alumno.

A nuestro juicio, el sistema de "enseמ̂anza activa", ideado y patrocinado por pedagogos del prestigio de John Dewey, Adolfo Ferreiro, Roger Cousinet y mu. chos otros, debe irse incorporando a la Pedagogia jurídica en forma mucho más acelerada de lo que es actualmente (4). Y creemos que la asignatura de

(4) En la Conferencia de Profesores Universita. rios: de las siete Universidades Chilenas, celebrada en Santiago en el año 1957, se acor- "práctica forense" se presta más que ninguna stra para este proceso de perfeccionamiento de la enseñanza del Derecho y de incorporación a ella de las tendencias modernas de la Pedagogia General (5).

Establecido ya que la asignatura de práctica forense tiene por objeto que el alumno de Derecho conozca los elementos del proces on su materialidad, que sc ejercite en el arte de desarrollar sus ideas a través de actuaciones procesales escritas, y que aprenda a expresarse en términos forenses; aclarado igualmente que todo el sistema de estudio de esta asignatura se desarrolla por medio de un proceso dialéctico con participación activa de los alumnos, pensamos que nada nos sirve más para aclarar exactamente la forma de desarrollo de una clase de "práctica forense" que decir que ella hace suyo el sistema complementario de enseñanza, tan empleado por las Universidades europeas, que se conoce con el nombre de "ejercitaciones".

Expresa Piero Calamandrei en su libro "La Universidad de Mañana" que en

do recomendar al Consejo de Rectores que se do recom la investigación sobre los métodos de enseńanza, tanto de los liceos metodos de Universidades, para estudiar objetivamente una posible "discrepancia grave entre la preparación cientifica básica que alcanzan los egresados del liceo y las exigencias minimas de la Universidad". En cumplimienminimas de la Universidad". Esta recomendación, el Consejo Universitario encomendo esta tarea al Instituto de Investigación Pedagógica de la Universidad de Chile, el que presentó en el año 1958 un interesante informe en el cual se establece que el método más frecuente de aprendizaje en nuestras Universidades sigue siendo ei de "conferencias". Concretamente, entre sus conclusiones figuran las siguientes: "10 Que los estudiantes participan muy poco en el proceso de aprendizaje, debido al exceso de alumvado $y$ escasez de personal docente $y$ auxiliar; $4^{\circ}$ Que se observa una tendencia a la acumulación de conocimientos teóricos, sin una base adecuada de investigación personal" (este estudio se referia exclusivamente a las asignaturas cientificasi.

15) Pensamos que la Pedagogia Universitaria es una simple rama de la Pedagogía General o. como to dice Vicror García Hoz. "son eta. pas diferentes de un proceso unico". Pedagogía Sistemat pag. $317 \%$. 
los esiudios universitarios deberá haber una "prevalencia de las ejercitaciones sobre las lecciones catedráticas". Y aclarando más su pensamiento agrega que "substituir la lección catedrática por la ejercitación no significa cambiar' la finalidad de la enseñanza, que deberá seguir siendo el derecho estudiado científicamente, esto es, sistemáticamente; significa, sí, substiłuir un método de enseñanza que condena a los alumnos a la inercia, a la parálisis mental, por un método que estimule sus iniciativas. que les dé la sensación de la independencia y el sentido de la responsabilidad en el trabajo".

Para probar el valor formativo que tiene la "Enseñanza Práctica" nos bastaría con recurrir a la historia de la enseñanza del Derecho, la cual nos revela que esta asignatura goza en la actualidad de todo tipo de consideraciones en la generalidad de los países europeos, en los países anglosajones e, ineluso, en la mayoría de los países americanos.

En Estados Unidos es sabido que en la mayoría de las Universidades el sistema normal de enseñanza del Derecho es el "método del caso" (case system) cuyas características $y$ peculiaridades coinciden en mucho con el sistema de "práctica forense" tal como se está empezando a hacer en nucstra Facultad. (6) .

En la Universidad de Madrid y en la de Barcelona la práctica forense es una asignatura independiente. Igualmente lo es en el Uruguay, donde el actual Decano de la Facultad de Montevideo ha sido durante largos años, y sigue siendo, profesor de "enseñanza práctica".

En Alemania cada día adquiere mayor importancia la enseñanza práctica del Derecho, y el "interés de los estudiantes y los benéficos resultados obtenidos han hecho que otras Universidades de Furopa adopten el sistema alemán de los casos prácticos" (7) . Algo parecido podemos decir de Italia y Francia.

\footnotetext{
(6) "Sobre las caracteristicas del método del ca so" puede verse. entre otros trabajos, la in. teresante Memoria de don Mario Chacón Zamora sobre "Pedagogla Jurídica Norteamericana".

(7) Francisco Oliver (citado por De Carlos).
}

Por su parte, er la Facultad de Derecho de Buenos Aires funciona desde hace largos años el Instituto de Enseñanza Práctica, dirigicto, primero, por el Profesor Héctor Lafaille, y desde 1941 por el Profesor Hugo Alsina.

Por lo demás, la necesidad de la "enseñanza práctica" del Derecho ha sido también planteada y defendida en interesantes trabajos de distinguidos jurisconsultos como Pietro Calamandrei, Franz von Liszt, Luis Jiménez de Azúa (8) Hugo Alsina, ete.

En el mismo sentido se han pronunciado también las Conferencias de Facultades de Derecho Latinoamerica. Y así, en la Primera Conferencia realizada en México en el año 1959 se declaró que los métodos de enseñanza del Derecho debían procurar "un adecuado equilibrio en la trasmisión de conocimientos teóricos y prácticos". Por su parte, en la Segunda Conferencia de Lima (1961) se acordó que " es obligación de las $\mathrm{Fa}$ cultades de Derecho impartir enseñanza práctica en el ciclo profesional". En todas estas conferencias se ha reconocido el carácter claramente docente de este tipo de actividades pedagógicas.

No obstante el valor de todas estas experiencias y opiniones (cuyo valor nadie podría negar) pensamos que la necesidad de las "clases prácticas" se deduce de un simple análisis de las finalidades do la enseñanza del Derecho, de un estudio elemental de la personalidad del educando y de una adhesión mínima a ciertos conceptos pedagógicos fundamentales.

Sostiene el Profesor Eduardo B. Carlos que "la labor docente de las Facultades

18) Luis Jiménez de Azúa ha escrito un interesante ensayo sobre La Metodologia Docente del Derecho Penal $y$ ia Misión de la Univer. versidad, en el cual hace una dura critica a la enseñanza del Derecho en ia generalidad de los países latinoamericanos. En este trabajo se refiere especialmente a sus experiencias en estudios de "casos" elr las "clases prácticas" llegando a sostener que "el solo me dio para que el alumno aprenda. sin esfuerzo ni desmayo. iss complicaciones tecnodogmaticas de la Parte General y las variadas especies de delitos es este metodo de resolucion de casos que en mi cátedra practiqué asiduamente". 
ha de realizarse, cualesquiera sean la naturaleza de los estudios o las técnicas profesionales que se enseñan, por medio de la cátedra, el seminario y los trabajos prácticos". Y agrega que "sólo en la armonía o correlación o, si se quiere, reciprocidad funcional de las mismas, siguiendo las modernas orientaciones pedagógicas universitarias, ha de llegarse a la formación del hombre culto a la vez que el profesional en la noble acepción de este vocablo" (Obra citada, pág. 41 y 62 ).

La asignatura de "Práctica Forense", tal como se encuentra ideada como instrumento para la enseñanze del Derecho. no es precisamente "ejercicio profesional" por parte de los estudiantes. Más aún, se pucde incluso concebir una asignatura de este tipo que sea totalmente ajena al ejercicio real de la abogacía por parte de los estudiantes (9). En esta forma, la "práctica forense", más que lo que el nombre pudiera insinuarnos, es sobre todo un sistema pedagógico destinado a la enseñanza del Derecho, con rasgos y características propias, diferente de la clase académica y distinta también de una mera práctica profesional. Esta asignatura tiene un campo propio de actividad (conocimiento del proceso en su materialidad, escritura y oratoria forense, etc.), un método de aprendizaje (1a lección diálogo) y un fin especifico y fundamental (el desarrollo en el alumno de su aptitud para "transferir" el conocimiento teórico a circunstancias o hechos humanos concretos). Es esto lo que define la asignatura y no su nombre.

Dicho en otros términos, "la enseñanza práctica constituye una de las formas didácticas como la Universidad imparte la enseñanza superior" (10).

(9) Esta afirmación no es obstáculo para que no patrocinemos este sistema y para que nos pronunciemos abiertamente. como lo veremos más adelante, en favor de que nuestra $E_{s}$ cuela de Derecho pueda tener en el futuro clínicas o Servicios destinados a que los alum nos atiendan algunos asuntos reales. A nues-

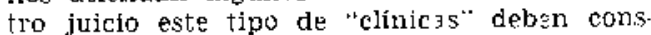
tituir necesario complemento en la enseñanza practica.
La circunstancia anteriormente anotada nos sirve para desvirtuar la mayor parte de las críticas que se hacen en nuestro país a esta asignatura, criticas que en la realidad inciden más en la etiqueta del ramo que en su contenido. Nosotros pensamos que lo único que cabe hacer para dar un veredicto sobre la llamada "práctica forense" es analizar si ella responde a una necesidad pedagógica y si sirve para contribuir a la formación de un profesional eficiente. Nosotros no dudamos en dar una respuesta afirmativa a estas preguntas.

Finalmente, queremos señalar que, a nuestro juicio, la clase práctica no tiene un método único de desarrollo. Por el contrario, como lo expresa Pietro $\mathrm{Ca}^{-}$ lamandrei en "La Universidad del Mañana", cada profesor debe crear el método que más adecuado le parezca $\mathrm{y}$ adquirirá en ello un arte propio. "Lo esencial es que la ejercitación, por variadas que sean sus formas, tienda siempre a dar al alumno activa participación en la Escuela, a transformarlo de inerte receptáculo del pensamiento ajeno en apasionado descubridor del pensamiento propio". Así el estudiante, mediante la ejercitación del pensamiento, deberá "educar su mente para afrontar por sí ios problemas nuevos y hallarles por si la solución".

Establecidas estas nociones generales sobre la asignatura de "práctica forense" nos es relativamente fácil señalar algunas de las ideas que deben guiar el desarrollo práctico de este tipo de clases, ideas que nos servirán también para caracterizar más exactamente el contenido y la esencia de csta asignatura.

a) La asignatura de "práctica forense" debe desarrollarse fundamentalmente a través del sistema "tutorial" de enseñanza. Nos parece fuera de toda duda

(10) Eduardo B. Carlos. Obra citada (pág. 151). Este autor, cstudiando la asignatura, expresa textualmente: "al dualismo ieoria y práctica ha de agregalse un tercer término: la técnica. Por consiguiente, la teoría enseña a "conocer", la proctica a "hacer" $y$, como lo subraya el procesalista Guasp, repitiendo la formula un tanto generalizada, la téc. nica a "saber hacer". (Pàg. 68). 
que una asignatura de este tipo nó pủede en ningún caso constituir una especie de monólogo en el cual exista un profesor que lo hable y lo haga casi todo. Por el contrario, la clase debe ser fundamentalmente un "diálogo" entre los alumnos y el profesor. Más aún, en este "diálogo" el personaje central y más importante no debe ser el profesor sino precisamente el alumno (11).

Han transcurrido muchos años desde el tiempo en que Sócrates dictaba clases a sus alumnos y les entregaba lo mejor de su personalidad sobresaliente, sin que ellos casi lo notaran. Desde entonces Sócrates es el profesor por excelencia y su sistema de enseñanza invade la Pedagogía toda.

Sócrates hablaba con sus alumnos, planteaba los problemas, despertaba su imaginación, a veces casi sugería una respuesta. Pero la solución del problema sólo la encontraba el alumno.

Quería que éste se diera cuenta de "que la verdad estaba en su propia capacidad para encontrarla, si la buscaba con el empeño y tiempo necesarios, $r$ chazando todos los criterios de autoridad y juzgando cada solución únicamente por la razón" (12). En esta forma el alumno desarrollaba su inteligencia, su imaginación, su espíritu crítico, su destreza. Y desarrollaba especialmente su personalidad, acostumbrándose a descubrir la verdad por su propio esfuerzo. Como si esto fuera poco, lo asi aprendico por el alumno era más definitivamente memorizado (13) .

Estas ideas muy elementales sirven para caracterizar el sistema "tutorial" de enseñanza, que debe constituir, a nuestro juicio, el método (crítico y a la vez constructivo) de desarrollo de una clase de "práctica forense". Es el sistema que Highet define como "diálo-

111 Planteando este problema, el profesor Lafaille tell el discurso inaugural del Instituto de Enseñanza Práctica de Argentina) dice que el alumno "debe ser conducido pero no reemplazado por el maestro".

(12) Gilbert Highet. "El Arte de Enseñar". Pág. 143.

(13) Expresaba Kant que "el maestro no debe enseñar pensamientos, sino debe enseñar a pensar". go", que Calamandrei ilama el "diálo. go lección" y que Eduardo Carlos individualiza como "reuniones cordiales donde las preguntas suceden a las respuestas, donde el pensamiento se robustece, el criterio juridico se forma, en fin, donde el alumno percibe direstamente la eficacia y la utilidad de la enseñanza" (obra citada, pág. 71).

La conveniencia de em!lear el sistema "tutorial" de enseñanza en la "clase práctica" no es sino una consecuencia de lo que anteriormente hẹmos expresa. do, en el sentido de que la asignatura que estudiamos supone necesariament? la participación activa del alumno $\mathrm{y}$, más concretamente, el empleo constante de su inteligencia, su imaginación y su espíritu crítico. Por lo mismo negamos todo valor formativo a una supuesta clase "práctica" que consista sólo en que los alumnos "visiten" determinadas of $i$ cinas, "vean" expedientes, "lean" sentencias $o$, incluso, hagan escritos sobre la base de formularios o de explicaciones demasiado completas del profesor.

Destacamos esto último porque, a nuestro juicio, existe un gran descono. cimiento de lo que debe ser una clase de "práctica forense", y no faltan quienes la conciban como una labor secundaria, limitada a un conocimiento externo de la realidad del proceso y del Tribunal, de sus costumbres y hasta de sus "triquinuelas". No. La clase práctica tiene valor sólo en la medida en que es activa y deja de tenerlo en cuanto se convierte en un mero ver, caminar, observar y copiar. El estudiante que se limita sólo a la "absorción de impresiones", sin preocuparse de su autoproducción, recogerá muy pocos beneficios pues "desarrollará su facultad adquisitiva, pero no su facultad creativa", qus es lo esencial (14).

Pues bien, el método a través del cual la "actividad" pedagógica debe expresarse y desarrollarse en la clase de "práctica forense" debe ser el del "diálogo-lección". Y en este caso este tipo de diá-

\footnotetext{
14.) Antonio Prunell. "Contribucion al Fstudio de li. Práctica y Didáctica del Derecho". Es tudios Ju'idicos en Memoria de Eduardo Couture.
} 
Logo tendrá siempre su comienzo en un hecho real y podrá elevarse posteriormeitte hasta el plano de la teoría o de la abstracción, en la medida en que ellas sirvan a la realidad que le dio origen.

b) - L La clase debe desarrollarse con un grupo reducido de alumnos. Aclarado ya que el método de desarrollo de una clase de "práctica forense" es el "diálogo", parece casi innecesario dar argumentos para comprobar que este tipo de clase debe desarrollarse con y por 11n grupo reducido de alumnos, no más de 15 o 20. ¿Cómo se pudiera pensar en un "diâlogo" activo en una sala repleta de alumnos y con un profesor sólo preocupado de mantener la disciplina?

Podríamos señalar varias razones que nos llevarían a la misma conclusión que sostenemos. En el deseo de ser breves serán omitidas. Pero queremos destacar una, que nos sirva precisamente para delimitar, aún en forma más exacta, el método de enseñanza que debe guiar una clase de "práctica forense". El sistema "tutorial" de enseñanza supone necesariamente un "conocimiento" y una "comunidad" entre profesores y alumnos. Pues bien, parece fuera de dudas que ese conocimiento y esa comunidad, bases del enriquecimiento recíproco, no pueden lograrse en un curso numeroso.

c.-Simultaneidad de la enseñanza práctica y teórica.-Bastante se ha discutido sobre si la enseñanza práctica y la teórica deben desarrollarse simultáneamente o si, por el contrario, la enseñanza práctica sólo debe darse en el último curso o después de terminada la formación doctrinaria del alumno. No han faltado tampoco quienes hayan ideado el sistema "alternativo" que supondría períodos intermedios en la enseñanza universitaria, que se dedicarían exclusivamente a la enseñanza práctica.

Por razones pedagógicas nos pronunciamos por el primero de los sistemas señalados, el de la "simultaneidad" $d$ ? ambas enseñanzas. La debida formación del alumno exige un desarrollo armóni- co de sus conocimientos y sus aptitudes, de su ciencia y de su arte Sólo en la "simultaneidad" se cumpic plenamente la "reciprocidad funcional" de que habla el profesor Eduardo B. Carlos.

Establecida esta simultaneidad en el desarrollo de los estudios teóricos y prácticos, deseamos aclarar dos puntos:

El primero, que normalmente el desarrollo de una materia en la clase práctica deberá hacerse después que el alumno haya adquirido en la clase teórica las nociones elementales para el debido aprovechamiento de la clase.

El segundo, que excepcionalmente deberán plantearse en la clase práctica problemas que correspondan a materias no aprendidas anteriormente por el alumno. Este último tipo de ejercicios tiene por objeto obligar al estudiante a investigar y estudiar, y lo coloca en la realidad de la profesión, que muchas veces plantea problemas totalmente nuevos y sobre materias desconocidas absolutamente por el abogado.

La necesidad de que la enseñanza teórica y práctica se desarrollen simultáneamente es una de las razones básicas para afirmar que la práctica profesjonal que hacen los egresados de Derecho en el Servicio de Asistencia Judicial ro podrán jamás suplir a la "enseñanza práctica" como asignatura docente universitaria. Esto al margen de la orientación más predominantemente social que didáctica que, por razones de hecho, tienen normalmente los Servicios de Asistencia Judicial.

d. -La asignatura de práctica forense tiene un carácter claramente docente y debe ser desempeñada por un profesor especializado.-En parte de este trabajo hemos expresado que el sujeto fundamental de una clase de "práctica forense" es el alumno y no el profesor, y queriendo señalai el papel aparentemento secundario de este último lo hemos designado intencionadamente como un ser desconocido a quien hemos llamado simplemente "alguien".

De lo anteriormente expuesto pudiera pensarse que la asignatura de "práctica forense" puede ser scrrida por cualquier 
persona escasa de conocímientos jurídicos y apenas con una relativa práctica en el quehacer diario de los Tribunales.

Sería éste un profundo error.

La verdad es, a nuestro juicio, que la asignatura de práctica forense necesita un profesor no sólo con buen criterio y con una buena formación jurídica, sino también, y especialmente, con condiciones pedagógicas notables que le permitan mantener un diálogo productivo con sus alumnos.

Es cierto que en este tipo de clases el profesor deberá aparentemente desempeñar un papel secundario frente a la actitud dinámica de los alumnos, pero no es menos efectivo también que ese papel aparentemente subalterno deberá ser desempeñado no por ignorancia, abulia o timidez, sino por una sentida y profunda adhesión a un sistema de enseñanza. No debemos olvidar, por lo demás, que corresponderá al profesor seleccionar debidamente el material didáctico para la clase y hacer ante los alumnos todas las exposiciones previas, y que será precisamente gracias a su: condiciones de maestro que podrá crearse en la sala de clases ese ambiente de interés y de estudio, de inquietud intejectual y de disciplina, que hará posible que el alumno desarrolle sus fotencialidades creadoras. Por lo demás, muchas veces el profesor deberá colocarse en la primera plana del debate, actuando con inteligencia y sin dogmatismo, y será justamente la sabiduría y personalidad del maestro factor indispensable para que tenga sobre sus alumnos el ascendiente moral que necesita para que se cumplan las finalidades básicas del sistema "tutorial" de enseñanza (15).

Se explica en esta forma que el carácter claramente docente de la enseñanza práctica haya sido reconocido por los especialistas en la materia, por las Universidades europeas $y$ anglosajonas $y$ por las Conferencias Latinoamericanas de Facultades de Derecho (16) .

15) Expresa Gilbert Highet que en la clase tu torial debe existir una intima relación entre el alumno y el profesor, en la cual éste "no puede ser ni tiránico ni frío y a menudo debe convertirse en ejemplo $y$ amigo del alunmo".
Es efectivo que "cátedra" es etimológicamente "asiento elevado desde donde el maestro explica". Pero en pleno siglo $\mathrm{XX}$ ya ningún pedagogo de importancia se atreve a defender este concepto $\mathrm{y}$ todos otorgan la jerarquía docente que corresponde a aquel profesor que, sobre la base de un diálogo con sus alumnos y actuando en la realidad, contribuye a desarrollar en los jóvenes, tanto sus conocimientos teóricos, como su técnica o habilidad para "transferir" los conocimientos adquiridos a situaciones o hechos concretos.

Creemos que la "enseñanza práctica" no podrá tener la importancia que se merece -y que la experiencia pedagógica le reconoce - sino en lá medida en que a los titulares de la asignatura se Ies đé y reconozca la jerarquía que a la asignatura le corresponde. Urge desterrar. de la mente de muchos de nuestros jóvenes la idea (en no pequeña parte inspirada en la educación secundaria) de que la "enseñanza práctica" constituye una actividad didáctica subalterna.

d. - El material para la clase debe ser seleccionado de casos reales.-Problema importante para una asignatura de "Práctica Forense" es encontrar el material apropiado para el desarrollo de la clase. En ta! sentido, para los efectos de esta asignatura, le negamos valor didáctico al llamado "caso de laboratorio", producto de la mente del tratadista o del profeser.

Consideramos muy útil que algunos de los casos con que deben trabajar los alumnos sean seleccionados de la vida real, en un Consultorio atendido por los mismos estudiantes. Los demás asuntos deberán ser sacados de los archivos o Pre-Archivos de los Juzgados, donde el profesor encontrará siempre matcria! abundante y de verdadero valor didáctico.

Así con el expediente en la mano, el alumno no sólo podrá analizar el proble-

16. Expresa Enrique Fornatti iobra citada, pag. 28): que "encarada la préctica forense con e! criterio $y$ la finalidad expuesta es de toda evidencia que su enseñanza sulo puede estar a cargo de la Universidad... bajo direccioll docente y responsable". 
má jurídico planteado en el proceso, sino que también podrá "sentir" el conflicto vivido por seres humanos que tienen nombres y apellidos.

e.-La enseñanza práctica debe desarrollarse en "comunidades" o "equipos" de trabajo, sustituyendo entre los alumnos los motivos de "competencia" por los de "cooperación".--No es novedad expresar que los tiempos presentes requieren, en todo tipo de actividades, de la cooperación entre sí de los individuos y de los grupos sociales. Es por ello que en la actualidad, tanto el trabajo manual como el intelectual, tanto el trabajo de investigación como el de realización, son ejecutados normalmente por "equipos" o "grupos" humanos.

Pues bien, si el hombre deberá en definitiva trabajar en "equipos" lo lógico es que la educación se encuentre orientada precisamente a ese tipo de trabajo. Y para ello, en todo establecimiento educacional deben existir ramos o actividades que fomenten el estudio comunitario.

Con razón sostiene Adolfo Ferriére, hablando del trabajo en "comunidades", que el "respeta la espontaneidad de los jóvenes, es funcional, completo, normal y diferenciado, apela a los sentidos y los pone al servicio de la interayuda humana".

A nuestro juicio, este tipo de trabajo en "comunidad" se presta especialmente para el desarrollo de las clases de "práctica forense". Y pensamos que justamente para el desarrollo del sentido comunitario de los alumnos debe el profesor normalmente plantear en las clases problemas o cuestiones que deben ser resueltas por todo el curso a través de un proceso de división del trabajo, de recoleccion de materiales, estudio, discusión y decisión en común.

En esta forma, con un sentido finalista de la enseñanza, en la clase de práctica forense "los métodos y motivos de competencia han de ser substituidos por los de cooperación" (17).

Algunos ejemplos nos podrán servir

(17) Palabras del Presidente de EE. UU. H. Hoo vel refiriendose a las transformaciones que debia sufrir la educación en Norteamerica. para aclarar mejor la iorma en que puede hacerse realidad este propósito:

"Se está pasando a un Curso la demanda, y el profesor plantea a los alum nos un caso en los términos simples y no jurídicos en que son normalmente expuestos por los clientes, (para estos efectos el profesor deberá haber estudiado en forma previa el expediente de donde ha sido extraído el caso y especialmente la prueba rendida).

Frente a estos hechos los alumnos deberán estudiar y debatir para llegar a alguna conclusión, por ejemplo, que estamos frente a un caso de simulación. El profesor, durante esta etapa de la clase, deberá substituír básicamente al "cliente", respondiendo a las preguntas de hecho que se le formulen y proporcionando al curso los documentos y antecedentes en relación con la demanda que debe iniciarse.

Establecido en forma definitiva que la acción que se intentará será la simulación, el grupo de trabajo se encontrará abocado, posiblemente, a la realidad de no poseer los conocimientos do:trinales o de jurisprudencia necesarios para redactar la demanda $\mathrm{y}$, más concretamente, para planear el desarrollo total deI juicio. Será ésta, entonces, la oportunidad para que el profesor encomiende a un grupo de alumnos la ubicación y estudio de todos los fallos que aparezcan sobre la materia en la Revista de Derecho y Jurisprudencia (cada alumno se hará cargo de cinco tomos, por ejemplo). Por su parte, otros alumnos se harán cargo de hacer el mismo trabajo con la Gaceta, la Revista de Derecho de la Universidad de Concepción, los "Fallos del Mes", etc. Este trabajo se complementará también con estudios doctrinales que deberán hacer los alumnos en relación con todos los puntos de dudas que se vayan planteando.

Con todo el material estudiado y reunide (se puede, incluso, pedir el desarchivo de los expedicntes más interesantes) deben realizarse nuevas reuniones y debates entre los alumnos, en las cuales se irán planteando los diversos aspectos (substantivos, procesales o prácticos) de la demanda. 
Hecho todo este trabajo previo, que constituirá al Curso en una verdadera "clínica juridica", cada alumno procederá a redactar una demanda.

En esta misma forma, a través de un trabajo de cooperación y de estudio metódico, deberá ir al curso viviendo cada etapa o actuación del proceso".

$Y$ podriamos preguntarnos: ¿cuántas injusticias se evitarian si inculcáramos en los alumnos y futuros abogados el hábito de estudiar conciensudamente los asuntos cuya defensa se les entrega?

g. - La atención de casos reales en Consultorios Jurídicos debe ser necesario complementi de la enseñanze práctica.Hemos expresado anteriormente que no son términos equivalentes "ejercicio profesional" y "práctica forense", denominación esta última que corresponde a todo un método de enseñanza del Derecho que sirve de complemento de las clases doctrinarias.

No obstante esta afirmación, consīderamos que, al menos en los últimos años, la clase de "práctica forense" debe trasladarse desde la sala de clases a la Clínica Jurídica (18) donde el alumno debe atender casos reales, generalmente conflictos o situaciones que afectan a personas de escasos recursos.

La importancia que tiene la atención y tramitación de juicios "reales" por parte de los alumnos es casi innecesario destacarla. El estudiante toma el primer contacto con el "hombre" y oyendo su versión del conflicto debe seleccionar los hechos con relevancia jurídica y debe "interpretar" lo que el "cliente" desea. Hecho este trabajo debe el alumno elegir la "acción" que es necesario intentar, actuando en todo este trabajo de "diagnóstico" asesorado por el profesor. Es este período de la "práctica tor'ense" el que más se presta para que el alumno desarrolle lo que Ihering llama el "talento operatorio" y que Fornatti califica como "concreción

(18) Esta afirmación no obsta a que desde el comienzo de los cursos los alumnos deban visitar $y$ conocer el Tribunal, las Cortes, los Archivos, etc. profesional que caracteriza al verdadero abogado".

Durante este período de la enseñanza práctica deberá el alumno igualmente concurrir al tribunal, presentar los escritos, copiar las providencias; seleccionar, preparar y ofrecer las pruebas; deberá participar activamente en las diligencias probatorias; tratar con el juez, con el secretario, con el empleado, etc.

Es aquí, en el Consultorio Jurídico, donde el mrincipiante verá con sus propios ojos "que el derecho no se produce por series, que para ser efjcaz la norma concreta debe "humanizarse" y bajar de las nubes, que la mayor parte de los casos no tienen dentro de los Códigos una solución preestablecida, que el jurista práctico vive combinando remedios para males siempre nuevos e imprevistos. Concebirá entonces nuestra profesión como algo mucho menos simple e ideológico, pero infinitamente más interesante y digno de apasionar los espíritus" (19) .

El Profesor Hugo Alsina, refiriéndose precisamente a este problema, ha expresado que "el conocimiento de la práctica judicial es indispensable y constituye una de las graves ausencias en la enseñanza de esta disciplina". $Y$ ha agregado que "el Instituto de Enseñanza Práctica que funciona en nuestra Facultad, importa un verdadero progreso en la enseñanza, pero no puede suplir la eficacia que deriva de la práctica del Tribunal, por breve que sea la experiencia" (20).

Enrique Fornatti se refiere también expresamente a la necesidad de que se haga por los estudiantes "práctica en el tribunal, donde los alumnos se ponen en contacto con un mundo nuevo para ellos, interviniendo en juicios "reales",

i19) Héctor Lafaille. Discurso Inaugural del Instituto de Enseñanza Práctica (Argentina). Citado por Eduardo B. Carlos.

20. Tratado de Derecho Procesal Civil y Comer. cial, pág. 169. Hago presente que se trata de la Edición de 1941, pues posteriormente el Insticuto ha evolucionado. A esia evolución se refiere expresamente Rafael Bielia en 51 . libro "La Abogacía", pág. 98, calificándoli de "encomiable". 
con audiencias de pruebas, declaraciones de testigos, absolución de posiciones, audiencias verbales, etc.". En esta forma, según palabras de don Oscar Davila, los jóvenes "adquieren la práctica judicial indispensable para el ejercicio de la profesión y, lo que vale mucho más, el conocimiento personal, directo y diario de la pobreza" (21), formando su "inteligencia, carácter y corazón".

Don Carlos A. Gaviola, en su "Clinica Jurídica", destaca también este úitimo aspecto de formación social de los estudiantes durante el período de "ejercicio profesional", y dice al efecto: "Allí el estudiante se impregna del verdadero espíritu, de compañerísmo y cooperación, que debe prevalecer en la profesió: aprende a rechazar causas sin fundamentos y a servir al cliente con desinterés. Se conpenetra, en otras palabras, de la razón social de su existencia como profesional, -lo remarco, pues muchos egresados pronto lo olvidan-- de que el diploma que recibe lo acredita para servir a la Sociedad y no para que la sociedad satisfaga sus intereses privados".

Muchas otras razones pudiéramos dar para destacar la importancia que tiene, desde un punto de vista didáctico, un cierto ejercicio profesional con "casos vivos" por parte de los alumnos. Sin embargo, deseamos referirnos sólo a un aspecto que se relaciona con la psicologia del estudiante y, concretamente, con el problema de la "motivación" de la enseñanza del Derecho.

No expresamos novedad de ninguna especie si decimos que la "motivación" es uno de los factores centrales en la dirección eficiente del proceso de aprendizaje. Precisamente por ello es obligación fundamental del profesor, y concretamente de la orientación de la enseñanza, buscar "motivaciones" lo suficientemente poderosas $\mathrm{y}$ persistentes como para que puedan los estudiantes sentirse impulsados con entusiasmo en su tarea de formación profesional.

En tal sentido creemos que para la

(21) El Colegio de Abogados de Chile, pág. 73 La frase citada se refiere a la practica que nacerl los egresados en el Servicio de Asistencia Judicial. generalidad de nuestros estudiantes de Derecho ningún motivo puede existir más poderoso que los impulsos en un sentido de perfección, que la conciencia exacta de que lo que están aprendiendo se encuentra al servicio del "hombre". Y pensamos que ningún camino es más apto para humanizar los estudios del Derecho que "traer al hombre" a nuestras Facultades a través de un cierto ejercicio profesional por parte de los alumnos.

La juventud es de por sí generosa, y la nuestra ha demostrado reiteradamente que es capaz de movilizarse cuando tiene "motivos" para ello. La vimes grande en los días del terremoto de Valdivia y la hemos seguido viendo asi en las campañas de alfabetización y en otras obras de bien común. Se diría que nuestros jóvenes andan buscando motivos para servir a sus semejantes.

Pensamos que ninguna tarea puede existir de mayor envergadura, desde un punto de vista didáctico, que tratar de aprovechar el sentido innato de servicio existente entre los estudiantes en un deseo de perfección profesional. (22).

No obstante lo que hemos expresado y toda la importancia que podría tener, a nuestro juicio, este período de verdadero "ejercicio profesional", pensamos que no debe hacerse en la Universidad una atención masiva de asuntos, que pudiera ser antipedagógica, sino simplemente debe tramitarse un número prudente de casos, muy bien estudiados y atendidos.

Deseamos, por último, hacer un paréntesis dentro de este tema para referirnos aquí a un punto que tiene una íntima relación con un posible ejercicio profesional por parte de los alumnos de Derecho, bajo la tuición directa de personal docente de la Universidad.

(22) Expresa el Profesor Antonio Prunell que "debe tomarse en las aulas, como punto de partida, el interés, para provocar $y$ determinar el máximo esfuerzo, al cual llegaremos paulatimamente $y$ en forma fácil. Siguiendo este proceso interés-esfuerzo. la atencion forzada se transformará inconcientemente en atención espontánea y voluntaria. lo que determinará un mayor poder de $\Gamma \mathrm{s}$ tención y asimilación". Obra citada, pág. 362 . 
Sabemos que en Chile la asistencia judicial de las personas modestas se encuentra a cargo de los abogados y procuradorcs de turno y del Servicio de Asistencia Judicial del Colegio de Abogados. Pues bien, para nadie que conozca de cerca este problema es un misterio que los organismos actualmente existentes (no obstante la eficierrcia y espíritu de sacrificio de su personol) no son suficientes para atender a vastos sectores de la población, que de nuestro orden jurídico apenas conocen su aspecto represivo.

En la ciudad de Santiago, veinte abogados, asistidos por un número reducido y siempre incierto de postulantes, deben hacerse cargo anualmente de la atención de más de 10.000 asuntos. En departamentos, como el de San Miguel, la situación es mucho más grave aún, y cuatro abogados se encuentran a cargo de la solución de los problemas civiles, sociales, penales, etc., de una población cercana a los 600.000 habitantes, en su mayoria faltos de recursos.

Urge buscar una solución para este grave problema. $Y$ tal vez no sea aventurado pensar que en un sistema de asistencia y cooperación de los Consultoríos Jurídicos del Colegio de Abogados y de las Escuelas de Derecho de nuestras Universidades podrían encontrarse en el futuro los elementos o factores básicos para una solución integral del problema. (23).

No es ésta la oportunidad para analizar más profundamente este tema; pero sí hemos creído de interés dejarlo insinuado como un nuevo factor positivo que es preciso tener en consideración cuando se plantea la posibilidad de un cierto ejercicio profesional real de la profesión por parte de los alumnos de Derecho.

23. E! Profesor don Aníbal Bascuñán Valdes en su libro sobre "Pedagog'ia Juridica", señalando el esquema a que podrta ajustarse el aprendizaje Práctico, señala como última etapa "la Asistencia Jurídica Gratuita den. tro del Servicio correspondiente del Colegio de Abogados. pero bajo un control mixto "en el que estaria representada la Facultad de Dereche" h) La enseñanza práctica no debe téner programas excesivamente rígidos.Pensamos que es absolutamente inconveniente que en este tipo de asignatura existan -como en la generalidad de los otros ramos - programas de estudio muy detallados. Estimamos, por el contrario, que estos programas, en caso de existir, deben limitarse a señalar algunas materias o instituciones muy importantes y dejar al criterio del profesor o de la dirección del Instituto respectivo la orientación de la clase.

Ya hemos visto con anterioridad que la clase de "práctica forense" no tiene por objeto enseñar al alumno a hacer todo tipo de escritos (en relación a cada materia) sino especialmente desarrollar en el educando su habilidad para aplicar el concepto o la ley a situaciones o hechos concretos. Esta idea central no puede naturalmente avenirse con programas rígidos, que pudieran constituir verdaderos "repasos" de la generalidad de las materias estudiadas en las clases teóricas.

"No enseñar demasiadas materias" y "lo que se enseña enseñarlo a fondo", según expresiones de Alfred Witehead, son, a nuestro juicio, las ideas básicas que deben guiar los programas de la asignatura que estudiamos.

i) La "práctica forense" debe ser una asignatura independiente y no debe haber una "clase práctica" en relación con cada ramo.- Se ha planteado por algunos la necesidad o la posibilidad de la existencia de "clases prácicicas" en relación con cada asignatura. Habría así una "práctica" en relación con el derecho civil, otra en relación con el derecho procesal, otra relativa al derecho comercial, pena1, etc.

A nuestro juicio, la "enseñanza práctica" debe ser unitaria, e independiente de cualquiera asignatura en particular. Y cuando más admitiría su división en la "práctica forense" (relacionada con juicios y tribunales) y la "práctica no forense" (relacionada con contratos, cstudins de títulos, etc.).

Las razones que nos llevan a sostener esta conclusión son básicamente dos: 
La primera tiene relación con lo que ya hemos expresado reiteradamente, en el sentido de que la "práctica forense" es fundamentalmente un método didáctico destinado a habituar al alumno en la "transferencia" de sus conocimientos abstractos a hechos o situaciones concretas. Pues bien, si lo básico de la clase en estudio es el desarrollo de determinadas aptitudes del alumno, sería un absurdo pensar en la necesidad de que éste experimentase con todo tipo de actuaciones y en todo tipo de materias. Habrá que pensar, por el contrario, que adquirida por el alumno la habilidad o el arte de la "transferencia" no tiene por que tener dificultades en la aplicación práctica de todo tipo de conocimientos. Como expresaba Goethe "saber y practicar bien una cosa da más educación que hacer y saber a medias cien cosas diferentes".

La segunda, porque creemos que hacer una práctica civil, otra procesal, otra comercial, etc., sería destruir la esencia misma del "hecho real", que normalmente es mezcla de todo, a veces incluso con complicaciones humanas o éticas de por medio. A nuestro juicio, la enseñanza práctica sólo adquiere su verdadero valor si se la considera como actividad didáctica, destinada a actuar en el campo de la "generalización" o de la síntesis de los conocimientos jurídicos. A este respecto expresa el Profesor Lafaille que en la Clínica Jurídica debe adquirirse "la noción integral del derecho que no llega jamás a perfeccionarse cuando se encara bajo uno solo de sus aspectos".

j) En la asignatura de "práctica forense" no deberá haber exámenes, pero sí calificaciones.-Desarrollándose la clase práctica en grupos reducidos, donde debe existir un contacto permanente entre el profesor y sus alumnos y donde el profesor tiene día a día la oportunidad de apreciar lo que cada alumno es y hace, parece totalmente innecesaria la existencia de "exámenes".

En la clase de "práctica forense" la calificación del alumno es simplemente el resultado de una apreciación de conjunto, hecha por el profesor, respecto del esfuerzo y aptitudes demostradas por cada alumno. Es también una apreciación del trabajo ejecutado por el pequeño grupo de alumnos con el cual se desarrolla la clase.

En esta forma la enseñanza práctica destierra de sus métodos de calificación el llamado "examen final" que tantas resistencias provoca y que merece tan serias críticas de parte de los pedagogos más modernos.

Dentro de este criterio central de supresión del "examen final" somos partidarios, sin embargo, de mantener en la "práctica forense" el mismo sistema de calificaciones o votaciones existente en la generalidad de las asignaturas. Naturalmente, no basamos esta afirmación en razones doctrinarias o de filosofía educacional - no podriamos hacerlosino en una simple razón práctica. Creemos que dentro de un sistema educacional donde gran parte de la motivación del estudiantado está dirigida hacia la obtención de determinadas calificaciones o distinciones, resulta particularmente difícil hacer experimentos aislados, más aún tratándose de una actividad docente a la cual todavía (desgraciadamente) no se le reconoce su verdadera importancia y jerarquía.

k) La clase de práctica forense se presta especialmente para inculcar en los alumnos nociones de ética profesional.-El profesor Enrique Fornatti, al referirse a la práctica forense y a la asistencia jurídica de pobres, expresa que, ante el conflicto planteado, el estudiante deberá ser siempre orientado "hacia la solución justa, la defensa de la ley y el culto de la verdad y la justicia". Y agrega que "es en el Servicio Juridico (última etapa de la enseñanza práctica) donde únicamente tiene cabiaa una cátedra de ética profesional. El profesor de trabajos prácticos, en presencia de casos reales, tiene siempre alguna ocasión de hacer comprender al alumno la finalidad social de la profesión y de inculcar, en cadil oportunidad propicia, las normas reguladoras de la conducta que, así aprendidas, dejarán huellas profundas y perdurables en el joven espíritu del principiante". En el 
mismo sentido se expresa el profesor Lafaille cuando dice que "la ética profesional tiene su natural cabida en nuestro laboratorio, permitiendo salvar una deficiencia de los programas actuales".

Nuestros estudiantes de Derecho sienten especial inquietud por todos los problemas relacionados con su futura conducta profesional. Prueba de ello es que en la clase de práctica forense siempre hemos tenido la oportunidad de presenciar diálogos entusiastas $y$ fecundos cuando los hechos y situaciones concretas de un expediente en estudio nos han abocado a la necesidad de analizar un problema de ética profesional. Es este un aspecto en que el profesor práctico siempre debe insistir.

En el terreno de Ia moral, las generalizaciones muchas veces son peligrosas $y$ es por ello que normalmente el análisis justo de un problema sólo puede hacerse frente a conflictos humanos concretos. Es aquí donde el caso puede ser mirado desde todos sus ángulos, a fin de que la conclusión nazca, no del análisis parcial de un valor moral que pueda estar en juego, sino del ariálisis y relación de todos los valores profesionales, éticos y filosóficos que deben guiar la conducta del profesional frente a la situación concreta que se le presenta.

Sostiene un autor que la Tierra se encuentra poblada por dos tipos de hombres: los que tienen imaginación, pero carecen de experiencia, y los que, teniendo experiencia, carecen de imaginación. Es ésta, en el fondo, una critica muy profunda a los sistemas educacionales vigentes.
Pensamos que esta crítica, en parte al menos, no es ajena a nuestra Pedagogia Jurídica. Deber nuestro es entonces trabajar porque, en lo posible, las cosas no sigan siendo así.

En tal sentido estimamos que una clase de "práctica forense" bien concebida es unn de los elementos más serios para hacer posible una reforma cie los estudios jurídicos. Basada esta asignatura en las tendencias modernas de la Pedagogía, tiende a desarrollar las aptitudes y la capacidad de los alumnos, utilizando sus propias energías; conectada, además, a la realidad de cada país es factor insubstituible para entregar a la sociedad un tipo de egresado que sea imaginativo y a la vez experto, que ame el Derecho, pero que también tenga conciencia exacta de que éste sólo tiene valor en la medida en que es útil para el hombre.

Finalmente, deseamos expresar que comprendemos perfectamente que no existe todavía en nuestro pais una experiencia lo suficientemente prolongada como para que se puedan sacar conclusiones definitivas sobre la "práctica forense" como actividad docente universitaria. Por lo mismo, no obstante el vigor con que hayamos podido defender algunas conclusiones, sabemos perfectamente que todo lo dicho se encuentra sujeto a ratificación o rectificación. En esta forma, este trabajo no tiene otro valor que el de tratar de despertar inquietud y promover un dialogo en relación con una actividad docente definitivamente incorporada a la Pedagogia Universitaria de nuestros tiempos. 